\title{
A Conceptual Framework for Incorporating Mentoring in the Clinical Supervision of International Counseling Students
}

\section{Daniel Bonnah Amparbeng $^{1}$ (i) $\cdot$ Yegan Pillay $^{1}$}

Accepted: 2 August 2021 / Published online: 23 August 2021

(C) The Author(s), under exclusive licence to Springer Science+Business Media, LLC, part of Springer Nature 2021

\begin{abstract}
There has been an increased number of international students attending universities in the United States, which has resulted in a growing number of international students in counseling programs. Cultural differences necessitate culturally appropriate supervision models for counselors and supervisors to utilize when working with international students. The authors identify and delineate the challenges and unique supervision needs of international counseling students and highlight the importance of mentoring as a culturally appropriate complementary supervision technique when supervising international counseling students. The authors propose the inclusion of mentoring with Bernard's discrimination model of supervision as a strategy to enhance the counseling skills of international students.
\end{abstract}

Keywords Counseling supervision · CACREP · International students · International counseling students $\cdot$ Mentoring

\section{Introduction}

Mentoring has been used over the years as a best practice technique to help a novice become an expert (Harvey \& Hill, 2004). Mentoring is defined as "a developmental partnership through which one person shares knowledge, skills, information, and perspective to foster the personal growth of someone else" (Butler et al., 2013, p. 2). Mentor relationships are dynamic, emotionally connected, and involves a reciprocal relationship in which the mentor shows deliberate and generative concern for the trainee beyond the mere acquisition of clinical skills (Johnson, 2003). Black et al. (2004) defined mentoring in counselor education as:

Daniel Bonnah Amparbeng

da512916@ohio.edu

1 Department of Counseling and Higher Education, Ohio University, 111 South Green Drive, Athens, $\mathrm{OH} 45701$, USA 
a nurturing, complex, long-term, developmental process in which a more skilled and experienced person serves as a role model, teacher, sponsor, and coach who encourages, counsels, befriends a less skilled person for the purpose of promoting the latter's professional and/or personal development. (p. 46)

Malone et al. (2010) indicated that although all graduate students can benefit from mentorship, mentoring is especially important for culturally and linguistically diverse (CLD) students who may experience numerous challenges as they transition into and navigate their graduate programs, such as lack of culturally responsive role models, limited faculty awareness of their needs and concerns, and lack of CLD community and professional networks. Mentors can play important roles in increasing international counseling students' sense of belonging and connection to the counseling profession.

Based on the increased number of international students in the counseling program (CACREP, 2016), the authors proposed an incorporation of mentoring into the clinical supervision of international students, in order to satisfy their unique needs and challenges. We highlight the internationalization of the counseling program in the United States, the unique challenges experienced by international students and expand on Bernard's discrimination model of supervision by proposing mentoring as an additional supervision strategy in the sections that follow.

\section{Internationalization of the Counseling Program}

Current statistics from the Institute of International Education (IIE) indicate that 1,095,299 international students were enrolled in American colleges and universities in the 2018/19 academic year (Institute of International Education, 2019). This represents an increase of $63 \%$ of international students enrolled in American colleges and universities in the last decade. In addition, international students constituted $5.5 \%$ of the total United States (U.S.) enrollment (Institute of International Education, 2019). The increase in demographics is also becoming evident in graduate-level counseling programs in the U.S. A report from CACREP (2016) indicated that of the 1741 doctoral students enrolled in CACREP accredited counseling programs, $4.14 \%$ were international students. The report also indicated that about $1 \%$ of master's students in CACREP accredited counseling programs were international students. Numerous studies have reported the challenges international students encounter in their academic environment, which influences their academic achievements and psychological wellbeing (Asempapa, 2019; Boafo-Arthur, 2014; Yoon \& Portman, 2004).

\section{Challenges of International Counseling Students}

$\mathrm{Ng}$ and Smith (2009) conducted a quantitative study involving 56 international counseling students (ICSs) and 82 domestic counseling students (DCSs), enrolled in programs from 22 and 16 states in the U.S. respectively. The researchers sought to explore the differences in ICSs and DCSs perceptions and experiences with issues pertinent to their training in the United States. The results indicated that ICSs 
experience increased academic challenges, difficulties in English proficiency, cultural adjustment difficulties, social/relational problems with peers, difficulties adapting to their clinical sites, discrimination by faculty members and fellow American trainees. Yoon and Portman (2004) reported that many international students are surprised by the racial discrimination they experience in the U.S. because they are accustomed to being members of the majority group in their home countries. Racial prejudice may adversely affect the acculturation process of international students and "can result in internalized or externalized anger, helplessness, prejudice toward the mainstream cultural group, and other forms of unresolved practical and emotional issues" (Westwood \& Ishiyama, 1991, p. 134). The process of acculturation also impacts both the social and psychological well-being of international students (Lee, 2018; Sullivan \& Kashubeck-West, 2015). During the acculturation process, international students may experience several barriers that adversely affect their social and academic communications participation. Asempapa (2019) asserts that these experiences result in increased acculturative stress during international students' field experience.

Many international students are not fluent in speaking English and hence experience challenges in the classrooms (Poyrazli \& Grahame, 2007). A study conducted by Sherry et al. (2010) involving 121 international students at the University of Toledo, indicated spoken language barriers among international students. Although most universities have put in place mechanisms to accommodate non-English speaking students, many international students still struggle with English and some jargon used in daily interactions with peers despite having this required proficiency level.

In light of the current racial tension in the United States and in certain European countries and the current climate of the COVID-19 pandemic, the aforementioned challenges that international students face may be exacerbated as a result of race and the negative associations being made with the origins of the virus and specific groups of international students. Therefore, various stakeholders, including graduate counseling programs and field supervisors, must be attuned to and sensitive to international students' experiences, especially during a student's practicum or internship when the interface with local communities is more likely to occur.

\section{The Role of Clinical Supervisors}

Supervision is an intervention provided by a more senior member of a profession to a more junior colleague(s) who typically (but not always) are members of the same profession to enhance the professional competence of the supervisee (Bernard \& Goodyear, 2014). Supervisors play a critical and essential role in assisting trainees to put into practice theories and knowledge acquired to develop their professional identity (Bernard \& Goodyear, 2014). There has been increased attention in recent years to the issues and dynamics associated with supervision and the need for supervisors to be multiculturally competent (Sangganjanavanich \& Black, 2009).

Regarding the numerous challenges that international students experience, culturally sensitive supervision techniques must be employed by supervisors when working with international students. This should be a priority as many counseling 
professionals who provide clinical supervision are masters-level practitioners who have not received formal supervision training (Borders et al., 2014). Consistent with these innovations concerning supervision, there have been calls within the mental health profession to increase multicultural competencies (Fickling et al., 2019; Lassiter et al., 2008; Ratts et al., 2016) and the frequency and quality of trainee mentoring (Johnson, 2002; Ponce et al., 2005).

\section{Multicultural Competent Supervision}

Multicultural competence is defined by an individual's awareness of, knowledge about, and skills in working within a wide range of cultural contexts (Ratts et al., 2016; Sue et al., 1992). Multicultural competence has been deemed as a critical component that serves individuals with different cultural backgrounds. The dynamics associated with these cultural differences can affect the content, process, and outcome of supervision, hence attending to multicultural issues in supervision has been strongly encouraged (Bernard \& Goodyear, 2014).

Fickling et al. (2019) argued that in order to ensure competent multicultural supervision, supervisors must incorporate The Multicultural and Social Justice Counseling Competencies (MSJCC) model developed by Ratts et al. (2016) to conceptualize clinical supervision. Even though the MSJCC were developed as counseling competencies, Fickling et al. (2019) advocated for the integration of MSJCC into the supervision relationship since supervision is a counseling specialty and a primary avenue for the professional development of counselors-in-training (Borders et al., 2014). They opined further that supervisors strive to grow as cultural beings and advocate for social justice and could benefit from using the MSJCC framework with their supervisees. The MSJCC contains four developmental domains: counselor self-awareness, awareness of client worldview, counseling relationship, counseling, and advocacy interventions (Ratts et al., 2016). For the purpose of clinical supervision, the word "supervisor" is substituted for counselor, "supervisee" for client, and "supervision" for counseling in the MSJCC model explain below.

\section{Supervisor Self-Awareness}

Most researchers have argued that multicultural and social justice competencies starts with self-awareness (Fickling et al., 2019; Lee \& Rodgers, 2009; Sue et al., 1992). Therefore, supervisors must assess and reflect on their intersectional identities and be cognizant of how they impact the supervision relationship with their supervisees. Through self-awareness, supervisors will be able to explore cultural dynamics with supervisees to ensure a successful supervision relationship.

\section{Supervisee Worldview}

The second developmental domain opined by Ratts et al. (2016) is supervisee worldview. Ratts et al. (2016) argued that when supervisors have self-awareness, they will 
appreciate and understand supervisees' worldviews and experiences. They argued that supervisors must be aware of how supervisees' identity and experiences influence the counseling relationship. For example, Constantine and Sue (2007) reported that supervisees from the minority group may have experienced stereotyping or racial bias in supervision and may be guarded with supervisors. When supervisors have self-awareness, they will be attuned to supervisees identity, worldviews, experiences, and provide appropriate support to supervisees without being judgmental.

\section{Supervisory Relationship}

The third developmental domain is the supervisory relationship (Ratts et al., 2016). The supervisory relationship has been deemed a critical component to effective and successful supervision, and supervisors have been cautioned to always attend to cultural concerns that impact the supervision relationship (Anaya \& Cole, 2001; Bhat \& Davis, 2007; Borders et al., 2014). The supervisory relationship includes development phases, roles and expectations of the supervision process, parallel processes, transference and countertransference, and multicultural issues (Fickling et al., 2019). Supervisors must therefore learn and understand how the cultural values, beliefs, biases, and the marginalized and privileged group status of both the supervisor and supervisee impact the supervision relationship.

\section{Supervision and Advocacy Interventions}

The final developmental domain is supervision and advocacy interventions (Ratts et al., 2016). Ratts et al. (2016) argued that multiculturally competent supervisors are better equipped to address supervisees' concerns and advocate for supervisees. They reported that supervisors might guide their supervisees to reflect on how internalized oppression might have helped or hindered their actions, how systemic policies impact them, and how their ethnicity or culture may influence their circumstances and the actions that can be implemented to change them. Fickling et al. (2019) argued that supervisors must know and accept that their roles are not only limited to in-session interventions, but also empowering and advocating for their supervisees.

We agree with the assertions made by Fickling et al. (2019) that in order to ensure multicultural competent supervision, supervisors ought to be mindful of the MSJCC model developed by Ratts et al. (2016) and incorporate the model in their supervisory work. In recognition of the multicultural competent supervision outlined above, we provide culturally sensitive supervision techniques that can be utilized when working with counselor trainees, specifically international counseling students. 


\section{Culturally Sensitive Supervision Techniques}

\section{Developing a Trusting Relationship with International Students}

Carl Rogers argued that a client-centered interpersonal relationship in which the counselor manifests an unconditional positive regard, congruence, and empathy provides the ideal atmosphere for change to occur (Rogers, 1957). Some researchers have also reported that the supervisory relationship and working alliance between supervisee and supervisor are significant (Bhat \& Davis, 2007), and it might be the most essential ingredient for successful supervision (Anaya \& Cole, 2001). Supervisors should therefore aim from the start of the supervision relationship to demonstrate empathy, genuineness, and unconditional positive regard when supervising international students. This can be achieved by supervisors expressing their understanding of the challenges that international students face and validating their feelings and thought processes. Supervisors should also communicate their availability to support supervisees by frequently checking on them to ensure they receive the support they need.

\section{Discussing Cultural Differences}

Another essential technique that supervisors should employ in addition to establishing a trusting relationship is acknowledging and discussing the cultural differences between the supervisor and the supervisee from the start of the relationship. Fickling et al. (2019) argued that in order to ensure multiculturally competent supervision, supervisors must broach cultural differences in the supervision relationship to invite supervisees to explore issues of diversity in the supervision relationship. Supervisors should therefore show interest in the cultural background of international student supervisees by initiating and openly discussing cultural differences and verbally indicating their willingness to help them navigate their training experiences due to their cultural differences.

\section{Setting Expectations}

In addition to the above, supervisors should make known to supervisees their expectations for supervision. This will allow supervisees to know what is expected of them and what to expect in the supervision relationship. Researchers have recommended that supervisors should collaborate with supervisees to establish roles, expectations for feedback, ways to attend to cultural misunderstandings, and ways in which unintentional racism could occur in their relationship (Borders et al., 2012; Chung et al., 2007; Daniels et al., 1999). Supervisors should therefore collaboratively set supervision expectations from the onset of the supervision relationship and engage in ongoing conversations about roles and expectations to help avoid any uncertainties and give supervisees confidence to pursue what is expected of them. 


\section{Periodic Evaluation of Supervision Relationship}

Finally, supervisors should periodically check in with supervisees and evaluate the supervision relationship by making judgments and decisions about how supervision is proceeding and its effects on supervisees. Periodically checking in and evaluating the supervision process with supervisees will enable supervisors to understand if supervisees are having challenges and if supervision goals are being achieved. Borders et al. (2014) indicated that supervisors should understand that evaluation is fundamental to supervision and provide opportunities for supervisees to offer verbal and written feedback about the supervisory process, including anonymous feedback when possible.

\section{Difference Between Supervision and Mentoring}

The supervision relationship involves an accountability process (Ming-sum Tsui et al., 2017) and hence involves expectations for technical guidance functions such as tracking progress and monitoring clinical performance. In other words, the supervisor/supervisee relationship involves a formal interaction that ensures that supervisees are properly monitored to guarantee no harm to their potential clients. The term supervision has historically emphasized training and evaluation (Johnson, 2007) and it carries an inherent connotation of transactional or hierachical relationship which is focused on need-based, short term, and solution oriented oversight where transfer of knowledge to an apprentice is primary (Duryee et al., 1996; Johnson, 2007). The hierarchical relationship and its associated distributions of power distinguish mental health supervision from mentoring. The power dynamic between supervisors and supervisees is primarily due to the gatekeeping role of supervisors. On the other hand, many mentor-mentee relationships are neither formal nor hierarchical, in part because the relationship is formed voluntarily and the mentor does not play the role of gatekeeping or an evaluator (Pillay et al., 2015). This leads to a more bonding and friendly relationship that does not occur in supervisor-supervisee relationships. In a phenominological study conducted by Sangganjanavanich and Black (2009) on the experiences of international counselors in training, they reported supervisor insensitivity, interpersonal isolation, inter-cultural confusion, and unique learning experiences as the four themes that emerged from the study. This therefore implies that a supervisor can assume and execute the role of training and evaluating a supervisee without a meaningful personal relationship between them. Duryee et al. (1996) reported that clinical supervision has historically been more technical than collaborative in many training settings. Therefore, it is important not to assume that supervision is synonymous with mentoring and that supervisors always become mentors. However, supervisors can assume and execute the role of a mentor by intentionally assisting supervisees' professional development and success by providing career, emotional, and psychosocial support to trainees (Johnson, 2007). For example, attending a conference together with supervisees, introducing supervisees to other professionals to help build their professional networks, advocating for supervisees at the clinical site, and supporting supervisees' personal growth. The mentor/mentee 
relationship is intentional and involves a longer intimate connection/relationship between the mentor and mentee, where the mentor provides ongoing guidance and support to the mentee beyond the mere acquisition of clinical skills. In view of the above, it could be seen that supervision is usually task-oriented and formal due to the evaluative and gate-keeping role of supervisors. On the other hand, mentoring involves a more intimate and caring for the mentee's long-term development.

\section{Benefits and Need for Mentoring as a Complementary Supervision Technique}

Mentoring can be valuable to trainees, and hence Weil (2001) referred to the provision of a mentoring culture and training approach as a moral obligation for departments and training centers. Meta-analyses results reveal that robust mentoring relationships are credited with numerous positive benefits (Eby et al., 2008; Kammeyer-Mueller \& Judge, 2008; Remaker et al., 2019). Mentored students show increased satisfaction with their graduate program and their career, greater productivity in their field of study, higher levels of skill development and competence, increased confidence and engagement, stronger professional identity, and higher levels of psychological health (Harvey \& Hill, 2004; Hollingsworth \& Fassinger, 2002). Clark et al. (2000) conducted a study involving 787 participants to explore mentoring relationships in doctoral programs. The authors reported that mentored participants indicated greater satisfaction with their doctoral program than non-mentored participants. These results also mirror Strayhom and Terrell's (2007) findings, who found a positive relationship between research-centered mentoring relationships and college satisfaction levels with Black student protegees. A study conducted by Shalka et al. (2019) involving international students across institutions in the United States indicated that international students benefitted from mentors who were faculty or student affairs professionals.

Researchers have also argued that the experiences of international students in counseling programs are unique from the experiences of international students in other programs due to the importance of interpersonal relationships, communication patterns, and cultural values in counseling programs (Interiano \& Lim, 2018; Mittal \&Wieling, 2006; Mori et al., 2009; Ng, 2006). Therefore, international counseling students must understand the traditions, beliefs, values, and non-verbal norms of U.S. culture. They must also understand and appreciate the role American history plays in the racial tensions that currently exist between different minority groups and the Anglo-American majority group in the U.S. (Interiano \& Lim, 2018; Ng \& Smith, 2009), in order to be effective and efficient when working with their future clients. Through mentorship, supervisors can create a safe, trusting, and supportive environment where international students can freely explore and process their challenges regarding the dominant Anglo-American culture.

This can be accomplished without compromising the gatekeeping role that clinical supervisors are charged with as their responsibility. Mentoring added to clinical supervision can also enhance the teaching and consultant roles that supervisors are expected to play. This will enable them to learn and develop the multicultural 
competence to work with their future clients, especially in a cultural context that is often unique based on their culture of origin norms and values. Given the above, it is entirely desirable and appropriate to argue that international counseling students who enjoy a strong mentorship relationship during their practicum and internship are likely to become more satisfied, successful, confident, and productive counseling professionals. The authors therefore recommend that mentoring becomes an integral part of the supervision strategies when supervising international counseling students. As Johnson (2007) points out, though clinical supervisors and mentors' roles are distinct, there are certainly opportunities for overlap in what he called "transformational supervision."

Transformational supervisors provide the roles of a traditional clinical supervision and are also dedicated to the supervisee's mentorship. Through transformational supervision, supervisors can incorporate the elements of mentoring, namely teaching, sponsoring, encouraging, counseling, and befriending (Anderson \& Shannon, 1988) to enhance the supervisory relationship. This can be achieved by facilitating a supportive and friendly environment that allows international students to explore any challenges and difficulties they might be encountering, sponsoring and helping international students to build effective and supportive networks in the counseling profession, respecting the personal and cultural experiences of international students, as well as their roles in the supervisory relationship, and establishing a continuing caring relationship. For that matter, the supervisor transitions from a relationship centered on transactions, be it an exchange of information, knowledge, among others, into building an emotional connection with international students through collaborative work. Supervisors should therefore execute the role of a mentor when supervising international counseling students.

\section{Integrating Mentoring into Bernard's Discrimination Model}

The discrimination model of supervision was developed in the mid-1970s and is considered to be the first model that novice supervisors encounter (Bernard \& Goodyear, 2014). This supervision model is chosen because it is adaptable and flexible for use in various settings such as universities, clinical and residential agencies, and public schools (Byrne \& Sias, 2010). As a result of its adaptability, it lends itself as a model that can be integrated with mentoring (Pillay et al., 2015). Bernard's discrimination model of supervision focuses on three foci of supervision as well as three supervisor roles. The focus areas are intervention, conceptualization, and personalization, while the three supervisory roles are teacher, counselor, and consultant. Bernard and Goodyear argued that after a supervisor has made judgments about a supervisee's ability within each focus area mentioned above, the supervisor must choose a role either as a teacher, counselor, or consultant to accomplish their supervision goals. Anderson and Shannon (1988) proposed five mentoring functions: teaching, sponsoring, encouraging, counseling, and befriending. They opined that mentors are inclined to be concern about the comprehensive welfare of their mentees. In view of this, it is reasonable to argue that supervisors' role as teacher, counselor, and consultant described in Bernard's discrimination model can be enriched 
by including the elements of mentoring: sponsoring, encouraging, and befriending proposed by Anderson and Shannon (1988). By incorporating these elements of mentoring into a supervisor's role, supervisors can transition into becoming what Johnson (2007) called transformational supervision. The following paragraphs detail the proposed elements of mentoring to be included in Bernard's discrimination model.

\section{Sponsoring}

Sponsoring within the mentoring context involves three key behaviors: protecting, supporting, and promoting (Anderson \& Shannon, 1988). Thus, the role of supervisors as sponsors can be achieved by protecting international students from engaging in any unethical behaviors due to their lack of knowledge about the new culture that could lead to litigations, affect their professional development, and negatively impact their clients. Supervisors can also protect international students from any discrimination from both clients and the organization by advocating for them. Supervisors can support international students by assisting them in professional development, such as co-presenting with them in conferences. Furthermore, supervisors can promote supervisees' personal and professional growth by introducing them to other clinical mental health professionals and counseling professional organizations to help them feel included and build their professional networks. Supervisors can also encourage international students to participate in professional organizations to facilitate their professional development.

\section{Encouraging}

Encouraging in the context of mentoring involves the process of affirming, inspiring, and positively challenging the behaviors of supervisees (Anderson \& Shannon, 1988). Supervisors can therefore encourage international students by affirming who they are and what they can do. They can endeavor to give voice and affirm international students by encouraging possibilities and ideas from them whenever possible to boost their confidence and foster dependency. They can inspire them by being role models through their exhibition of multicultural competencies and other pertinent professional skills. Supervisors can also offer challenges by inviting international students to be involved in growth-producing experiences and encourage international students to reflect on their inner wisdom to formulate appropriate solutions to clinical dilemmas, rather than providing answers whenever possible.

\section{Befriending}

Befriending refers to a relationship that transcends beyond the supervisory relationship. This mentoring element could be challenging for supervisors as many ethical codes of professional organizations caution against relationships that could be deemed dual or multiple (Pillay et al., 2015). However, befriending, as suggested by Anderson and Shannon (1988), involves two significant behaviors, namely accepting 
and relating. Accepting and relating essentially means that international students are accepted for who they are, without attaching any form of judgment and prejudices. This level of acceptance is essential to both the supervisory and mentoring relationship given the fact that there is a higher tendency for international students to experience homesickness, loss, and social isolation (Johnson \& Sandhu, 2007). As a friend, supervisors can invite international students to community events and other social gatherings that can facilitate their professional and personal wellbeing. Supervisors can also make international students know that they understand their challenges, and they are available to support them. By incorporating mentoring into Bernard's Discrimination model of supervision, supervisors can perform the functions of sponsoring, encouraging, and befriending in addition to the supervisory roles of teaching, counseling, and consultation articulated in the discrimination model. This will enrich the supervisory relationship and promote effective supervision experience for supervisees, especially international counseling students.

\section{Establishing a Mentorship Relationship}

\section{Develop a Plan}

To establish and maintain the mentorship relationship effectively, supervisors should discuss a mentorship plan with international counseling students. Supervisors should not automatically assume that international students fully understand the form and functions of mentoring and possess the required skills to be good mentees. In a study conducted by Chung et al. (2007) to explore multicultural issues in mentoring, the authors reported that the participants' racial and ethnic backgrounds influenced their perceptions and expectation of mentoring. These findings imply that one's cultural affiliations impacts the supervisory relationship. Supervisors should therefore collaborate with international students and engage in open and honest discussions concerning the expectations, strengths, limitations, differences, and responsibilities of both parties in the mentoring relationship. Through these discussions, supervisors should collaborate with international students to develop a mentorship plan and evaluate the level of commitment deemed necessary by both parties. This will allow supervisors to understand what international students expect from the mentoring relationship, discuss and clarify any unrealistic expectations, identify any areas of limitations, and explicitly agree on what the mentoring relationship will entail to avoid any confusion and misunderstandings.

\section{Active Engagement}

The supervisor must be actively engaged in the supervisory relationship. At the outset of any formal supervision relationship, both parties often gravitate to hierarchical or formal relationship styles, sometimes described as a mastery model of supervision (Johnson, 2007; Ponce et al., 2005). However, through active engagement by supervisors, they will be able to build a collaborative relationship with international 
counseling students and transition to become mentors. Supervisors can actively engage in the relationship by taking the initiative to demonstrate their support and commitment to the growth of international students. This can be achieved by supervisors paying attention to the experiences and welfare of international students, investing in learning their unique cultural heritage, appreciating their uniqueness within the dominant culture, affirming their value to their department by involving them in decision-making and validating their feelings and thoughts as well as their personal goals. Active engagement could also be demonstrated by supervisors investing in the professional growth of international students through co-presenting with them in conferences, introducing them to other clinical mental health professionals and counseling professional organizations to help them feel included and build their professional networks.

\section{Multicultural Competency}

Furthermore, supervisors must be culturally competent and race conscious. Supervisors should appreciate the impact of culture, race, and ethnicity in the supervision relationship. Malone et al. (2010) argued that mentees who identify a mentor whom they feel comfortable to discuss race, cultural issues, and the intersection between gender and ethnicity are ideal mentor candidates for international students. Therefore, in establishing a mentorship relationship, supervisors ought to demonstrate multicultural competencies by being cognizant of their identities and worldviews and how it impacts their work with international students (Fickling et al., 2019). For example, Constantine and Sue (2007) reported that supervisees from the minority group may have experienced stereotyping or racial bias in supervision and may be guarded with supervisors. In such a situation, supervisors can demonstrate multicultural competencies by being attuned to international students' identity, worldviews, and experiences. This will enable supervisors to provide appropriate support to international student supervisees by validating their experiences and supporting their professional growth because of the stressors, discrimination, and adjustment issues they encounter. This is important as prior research on cross race/ethnicity mentoring has indicated that relationships are more effective when both parties are comfortable discussing their differences openly (Malone et al., 2010; Schlosser \& Foley, 2008).

\section{Build a Relationship}

Supervisors should aim from the beginning of supervision to build an effective relationship through demonstrating empathy, genuineness, and unconditional positive regard when supervising international students. Some researchers have reported that the supervisory relationship and working alliance between supervisees and supervisors are significant and might be the most important ingredient for successful supervision (Anaya \& Cole, 2001; Bhat \& Davis, 2007). Supervisors can build an effective relationship with international students through informal conversations over coffee, attending conferences together, and effective self-disclosure of the 
supervisor's successes and failures. However, supervisors should be mindful of the power dynamics in the relationship and not abuse their authority by making supervisees engage in activities that are of no interest to them.

\section{Recommendations for Future Research}

The authors recommend that empirical studies are conducted to evaluate the effectiveness of mentoring as a complementary supervision strategy or model regarding international students' in U.S. based counseling programs. This will help build on and possibly adjust the presented techniques on supervision specific for international counseling students and U.S. supervisors. Future research should also include both quantitative and qualitative approaches with international counselors-in-training in U.S. institutions. Future research could also compare the experiences of international counseling students who experience mentoring to those with no mentorship. These would help in exploring international students' needs as well as their experiences with counselor training and supervision.

\section{Conclusion}

The number of international students is increasing in the United States' counseling programs; hence supervisors must be intentional about the discharge of their roles. Historically, mentorship has played an essential role in providing support, guidance, and professional development in the lives of culturally and linguistically diverse students. The authors believe that mentoring should be an integral part of clinical supervision strategies when supervising international counseling students. The authors recommend that being intentional about incorporating mentoring in the supervision relationship has the potential to enhance an effective supervision experience for all counseling students, especially international counseling students, due to their unique training experiences in the United States. By incorporating mentorship into the supervision relationship, international counseling students can explore and process their challenges and receive adequate guidance and opportunity to nurture their social and networking repertoire. This will lead to increased satisfaction in international counseling students' supervision experience and improved professional identity development.

Johnson (2007) argued that supervision is most effective when emotional support and technical/clinical skill development are combined in a single supportive relationship. Therefore, we believe that in supervising international students, it will be appropriate for supervisors to execute the additional elements of mentoring outlined in this article to provide a more meaningful training experience for international counseling students.

\section{Declarations}

Conflict of interest The authors have no known conflict of interest to disclose. 


\section{References}

Anaya, G., \& Cole, D. (2001). Latina/o student achievement: Exploring the influence of student-faculty interactions on college grades. Journal of College Student Development, 42, 3-14. Retrieved July 26, 2021, from https://psycnet.apa.org/record/2001-16133-001

Anderson, E. M., \& Shannon, A. L. (1988). Toward a conceptualization of mentoring. Journal of Teacher Education, 39(1), 38-42. https://doi.org/10.1177/002248718803900109

Asempapa, B. (2019). Mentoring and supervising international students in school counseling programs. Journal of International Students, 9(3), 912-928. https://doi.org/10.32674/jis.v9i3.746

Bernard, J., \& Goodyear, R. (2014). Fundamentals of clinical supervision (5th ed.). Pearson Education Inc.

Bhat, C. S., \& Davis, T. E. (2007). Counseling supervisors' assessment of race, racial identity, and working alliance in supervisory dyads. Journal of Multicultural Counseling and Development, 35(2), 80-91. https://doi.org/10.1002/j.2161-1912.2007.tb00051.x

Black, L. L., Suarez, E. C., \& Medina, S. (2004). Helping students help themselves: strategies for successful mentoring relationships. Counselor Education and Supervision, 44(1), 44-55. https://doi. $\operatorname{org} / 10.1002 / \mathrm{j} .1556-6978.2004 . t b 01859 . x$

Boafo-Arthur, S. (2014). Acculturative experiences of Black-African international students. International Journal of Advanced Counseling, 36(2), 115-124. https://doi.org/10.1007/ s10447-013-9194-8

Borders, L. D., Glosoff, H. L., Welfare, L. E., Hays, D. G., DeKruyf, L., Fernando, D. M., \& Page, B. (2014). Best practices in clinical supervision: Evolution of a counseling specialty. The Clinical Supervisor, 33(1), 26-44. https://doi.org/10.1080/07325223.2014.905225

Borders, L. D., Wester, K. L., Granello, D. H., Chang, C. Y., Hays, D. G., Pepperell, J., \& Spurgeon, S. L. (2012). Association for counselor education and supervision guidelines for research mentorship: development and implementation. Counselor Education and Supervision, 51(3), 162-175. https:// doi.org/10.1002/j.1556-6978.2012.00012.x

Butler, S. K., Evans, M. P., Brooks, M., Williams, C. R., \& Bailey, D. F. (2013). Mentoring African American men during their postsecondary and graduate school experiences: Implications for the counseling profession. Journal of Counseling \& Development, 91(4), 419-427. https://doi.org/10. 1002/j.1556-6676.2013.00113.x

Byrne, A. M., \& Sias, S. M. (2010). Conceptual application of the discrimination model of clinical supervision for direct care workers in adolescent residential treatment settings. Child \& Youth Care Forum, 39(3), 201-209. https://doi.org/10.1007/s10566-010-9100-z

Chung, R.C.-Y., Bemak, F., \& Talleyrand, R. M. (2007). Mentoring within the field of counseling: a preliminary study of multicultural perspectives. International Journal for the Advancement of Counselling, 29(1), 21-32. https://doi.org/10.1007/s10447-006-9025-2

Clark, R. A., Harden, S. L., \& Johnson, W. B. (2000). Mentor relationships in clinical psychology doctoral training: results of a national survey. Teaching of Psychology, 27(4), 262-268. https://doi.org/ 10.1207/S15328023TOP2704_04

Constantine, M. G., \& Sue, D. W. (2007). Perceptions of racial microaggressions among Black supervisees in cross-racial dyads. Journal of Counseling Psychology, 54, 142-153. https://doi.org/10.1037/ 0022-0167.54.2.142

Council for Accreditation of Counseling and Related Educational Programs. (2016). 2016 Standards. Retrieved August 17, 2021, from http://www.cacrep.org/wp-content/uploads/2018/05/2016-Stand ards-with-Glossary-5.3.2018.pdf

Daniels, J., D’Andrea, M., \& Kim, B. S. K. (1999). Assessing the barriers and changes of cross-cultural supervision: A case study. Counselor Education and Supervision, 38(3), 191. https://doi.org/10. 1002/j.1556-6978.1999.tb00570.x

Duryee, J., Brymer, M., \& Gold, K. (1996). The supervisory needs of neophyte psychotherapy trainees. Journal of Clinical Psychology, 52, 663-671. https://doi.org/10.1002/(SICI)1097-4679(199611) 52:6\%3c663::AID-JCLP8\%3e3.0.CO;2-L

Eby, L. T., Allen, T. D., Evans, S. C., Ng, T., \& Dubois, D. (2008). Does mentoring matter? A multidisciplinary meta-analysis comparing mentored and non-mentored individuals. Journal of Vocational Behavior, 72, 254-267. https://doi.org/10.1016/j.jvb.2007.04.005 
Fickling, M. J., Tangen, J. L., Graden, M. W., \& Grays, D. (2019). Multicultural and social justice competence in clinical supervision. Counselor Education and Supervision, 58(4), 309-316. https://doi. org/10.1002/ceas.12159

Harvey, A., \& Hill, R. B. (2004). Africentric youth and family rites of passage program: Promoting resilience among at-risk African American youths. Social Work, 49, 65-74. https://doi.org/10.1093/sw/ 49.1.65

Hollingsworth, M. A., \& Fassinger, R. E. (2002). The role of faculty mentors in the research training of counseling psychology doctoral students. Journal of Counseling Psychology, 49, 324-330. https:// doi.org/10.1037/0022-0167.49.3.324

Institute of International Education. (2019). Open doors report on international educational exchange. Retrieved July 21, 2021, from https://opendoorsdata.org/annual-release/

Interiano, C. G., \& Lim, J. H. (2018). A “Chameleonic” identity: Foreign-born doctoral students in U.S. counselor education. International Journal for the Advancement of Counselling, 40(3), 310-325. https://doi.org/10.1007/s10447-018-9328-0

Johnson, L. R., \& Sandhu, D. S. (2007) Isolation, adjustment, and acculturation issues of international students: Intervention strategies for counselors. In HD Singaravelu \& M Pope (Eds), A handbook for counseling international students in the United States (pp. 13-35). American Counseling Association. Retrieved July 25, 2021, from https://psycnet.apa.org/record/2007-07232-002

Johnson, W. B. (2002). The intentional mentor: Strategies and guidelines for the practice of mentoring. Professional Psychology: Research and Practice, 33, 88-96. https://doi.org/10.1037/0735-7028. 33.1 .88

Johnson, W. B. (2003). A framework for conceptualizing competence to mentor. Ethics and Behavior, 13, 127-151. https://doi.org/10.1207/S15327019EB1302_02

Johnson, W. B. (2007). Transformational supervision: When supervisors mentor. Professional Psychology: Research and Practice, 38(3), 259. https://doi.org/10.1037/0735-7028.38.3.259

Kammeyer-Mueller, J. D., \& Judge, T. A. (2008). A quantitative review of mentoring research: A test of a model. Journal of Vocational Behavior, 72, 269-283. https://doi.org/10.1016/j.jvb.2007.09.006

Lassiter, P. S., Napolitano, L., Culbreth, J. R., \& Ng, K. M. (2008). Developing multicultural competence using the structured peer group supervision model. Counselor Education and Supervision, 47(3), 164-178. https://doi.org/10.1002/j.1556-6978.2008.tb00047.x

Lee, A. (2018). Clinical supervision of international supervisees: Suggestions for multicultural supervision. International Journal for the Advancement of Counselling, 40(1), 60-71. https://doi.org/10. 1007/s10447-017-9312-0

Lee, C. C., \& Rodgers, R. A. (2009). Counselor advocacy: Affecting systemic change in the public arena. Journal of Counseling \& Development, 87, 284-287. https://doi.org/10.1002/j.1556-6678.2009. tb00108.x

Malone, C., Jacobs, D., \& Sullivan, A. (2010). Mentorship for culturally and linguistically diverse school psychology graduate students. NASP Communique, 39. Retrieved July 21, 2021, from https://bit.ly/ 3rtRKuA

Mittal, M., \& Wieling, E. (2006). Training experiences of international doctoral students in marriage and family therapy. Journal of Marital and Family Therapy, 32(3), 369-383. https://doi.org/10.1111/j. 1752-0606.2006.tb01613.x

Mori, Y., Inman, A. G., \& Caskie, G. I. (2009). Supervising international students: Relationship between acculturation, supervisor multicultural competence, cultural discussions, and supervision satisfaction. Training and Education in Professional Psychology, 3(1), 10. https://doi.org/10.1037/a0013 072

$\mathrm{Ng}$, K. M. (2006). Counselor educators' perceptions of and experiences with international students. International Journal for the Advancement of Counseling, 28(1), 1-19. https://doi.org/10.1007/ s10447-005-8492-1

Ng, K., \& Smith, S. D. (2009). Perception and experiences of international trainees in counseling and related programs. International Journal for the Advancement of Counselling, 31(1), 57-70. https:// doi.org/10.1007/s10447-008-9068-7

Pillay, Y., Fulton, B., \& Robertson, T. (2015). A conceptual framework for incorporating mentoring in the clinical supervision of mental health professionals. In A. Howley \& M.B. Trube. Mentoring for the Professions: Orienting Toward the Future (pp.353-362). Charlotte, NC: Information Age Publishing. Retrieved July 26, 2021, from https://tinyurl.com/ys4sz5as 
Ponce, A. N., Williams, M. K., \& Allen, G. J. (2005). Toward promoting generative cultures of intentional mentoring within academic settings. Journal of Clinical Psychology, 61, 1159-1163. https:// doi.org/10.1002/jclp.20157

Poyrazli, S., \& Grahame, K. M. (2007) Barriers to adjustment: needs of international students within a semi-urban campus community. Journal of Instructional Psychology, 34(1), 28-45. Retrieved March 10, 2021, from https://www.nheducatorresources.com/eds/detail?db=a9h\&an=24729499

Ratts, M. J., Singh, A. A., Nassar-McMillan, S., Butler, S. K., \& McCullough, J. R. (2016). Multicultural and social justice counseling competencies: guidelines for the counseling profession. Journal of Multicultural Counseling and Development, 44(1), 28-48. https://doi.org/10.1002/jmcd.12035

Remaker, D. N., Gonzalez, M. M., Houston-Armstrong, T., \& Sprague-Connors, G. (2019). Women of color and mentorship in graduate training. Training and Education in Professional Psychology. https://doi.org/10.1037/tep0000297

Rogers, C. R. (1957). The necessary and sufficient conditions of therapeutic personality change. Journal of Consulting Psychology, 21, 95-103. https://doi.org/10.1037/h0045357

Sangganjanavanich, V. F., \& Black, L. L. (2009). Clinical supervision for international counselors-intraining: Implications for supervisors. Journal of Professional Counseling: Practice, Theory \& Research, 37(2), 52-65. https://doi.org/10.1080/15566382.2009.12033860

Schlosser, L. Z., \& Foley, P. F. (2008). Ethical issues in multicultural student-faculty mentoring relationships in higher education. Mentoring \& Tutoring: Partnership in Learning, 16(1), 63-75. https:// doi.org/10.1080/13611260701801015

Shalka, T. R., Corcoran, C. S., \& Magee, B. T. (2019). Mentors that matter: international student leadership development and mentor roles. Journal of International Students, 9(1), 97-110. https://doi.org/ 10.32674/jis.v9i1.261

Sherry, M., Thomas, P., \& Chui, W. H. (2010). International students: A vulnerable student population. Higher Education, 60(1), 33-46. https://doi.org/10.1007/s10734-009-9284-z

Strayhorn, T. L., \& Terrell, M. C. (2007) Mentoring and satisfaction with college for black students. Negro Educational Review 58(1-2): 69-83. Retrieved July 26, 2021, from https://eric.ed.gov/?id= EJ777562

Sue, D. W., Arredondo, P., \& McDavis, R. J. (1992). Multicultural counseling competencies and standards: a call to the profession. Journal of Counseling \& Development, 70(4), 477-486. https://doi. org/10.1002/j.1556-6676.1992.tb01642.x

Sullivan, C., \& Kashubeck-West, S. (2015). The interplay of international students' acculturative stress, social support, and acculturation modes. Journal of International Students, 5(1), 1-11. https://doi. org/10.32674/jis.v5i1.438

Tsui, M.-S., O’Donoghue, K., Boddy, J., \& Pak, C.-M. (2017). From supervision to organisational learning: a typology to integrate supervision, mentorship, consultation and coaching. British Journal of Social Work, 47(8), 2406-2420. https://doi.org/10.1093/bjsw/bcx006

Weil, V. (2001). Mentoring: Some ethical considerations. Science and Engineering Ethics, 7, 471-482. https://doi.org/10.1007/s11948-001-0004-Z

Westwood, M., \& Ishiyama, F. (1991). The communication process as a critical intervention for client change in cross-cultural supervision. Journal of Multicultural Counseling and Development, 18, 163-171. https://doi.org/10.1002/j.2161-1912.1990.tb00447.x

Yoon, E., \& Portman, T. A. (2004). Critical issues of literature on counseling international students. Journal of Multicultural Counseling and Development, 32, 33-44. https://doi.org/10.1002/j.2161-1912. 2004.tb00359.x

Publisher's Note Springer Nature remains neutral with regard to jurisdictional claims in published maps and institutional affiliations. 